\title{
An Investigation on the Effect of Cutting Parameters in CNC Plasma Cutting Process for Carbon Steel
}

\author{
Pham Thi Hang ${ }^{1}$, Nguyen Thi Chau ${ }^{1}$, An Duong Khang ${ }^{2}$, \\ Nguyen Hoang Anh ${ }^{3}$ \& Pham Hong Son ${ }^{4}$
}

${ }^{1}$ Faculty of of Engineering, Vietnam National University of Agriculture, Hanoi 131000, Vietnam

${ }^{2}$ Class K61CKCTM, Vietnam National University of Agriculture, Hanoi 131000, Vietnam ${ }^{3}$ Class K61KTCKP, Vietnam National University of Agriculture, Hanoi 131000, Vietnam

${ }^{4}$ Class K62KTCKP, Vietnam National University of Agriculture, Hanoi 131000, Vietnam

\begin{abstract}
The effect of technological parameters such as gas pressure, cutting current, standoff distance, and cutting speed on the cutting surface quality of CNC plasma cutting process was investigated. The experiment was carried out by Bruco CNC plasma cutting machine for CT3 steel with different thicknesses. The quality characteristics examined included the ability to cut out samples, the slag formation on the surface, the surface roughness, and the cut angle. The analysis of the results was made using the Taguchi method in order to determine the contribution of each-individual parameter to the cutting quality, especially surface roughness. The obtained results show that the value of cutting current should be set up at a real value in order to cut out of the sample. The air pressure strongly affected the slag formation. The surface roughness was mainly affected by the standoff distance and air pressure, whereas the cutting speed and cutting current were the minor influencing parameters.
\end{abstract}

\section{Keywords}

Manufacturing, plasma cutting, surface roughness, Taguchi method

\section{Introduction}

The plasma process for cutting was developed approximately thirty years ago (Ilii et al., 2010). In this process, a high energy stream of dissociated, ionized gas, known as plasma, was used as the heat source for cutting metals such as carbon steel, stainless steel, aluminum, copper, and other metals or alloys using a plasma torch (Bhowmicka et al., 2018; Salonitisa et al., 2012). Generally, an inert gas is blown at a high speed out of a nozzle and, at the same time, an electrical arc is formed through that gas from the nozzle to the surface being cut, turning some of that gas into plasma. This plasma torch is sufficiently hot in order to melt the metals or alloys. As a result, the 
metal might be cut away from the beginning plate. A model for the plasma arc cutting principle is expressed in Figure 1 (Tsiolikas et al., 2016). The inert gases usually used in cutting metals are dry air, Nitrogen, Argon/Hydrogen, and Oxygen gas. Air plasma is mostly used on ferrous or carbon-based materials to obtain good quality with a faster cutting speed (Teja et al., 2015). Meanwhile, Nitrogen plasma provides better cut quality on non-ferrous materials such as stainless steel. Argon/Hydrogen is applied in the case of thicker stainless steel. When using Oxygen gas, the quality of the cutting surface obtained is higher with very smooth finishes and minimizes nitride build-up on the cut surface (Kechagias et al., 2014).

The advantage of the plasma cutting method is that it can cut the thicker materials at lower cutting speeds compared to other conventional arc cutting methods (Bhowmicka et al., 2018; Patela et al., 2018). Moreover, the plasma cutting method is able to achieve high quality for cutting kerf with complex profiles. In addition, it is possible to mechanize and automate the cutting process. Therefore, nowadays, plasma cutting technology is widely used in mechanical manufacturing with computer numerical control (CNC) to improve productivity as well as enhance cutting quality. In the process of $\mathrm{CNC}$ plasma cutting, technological factors such as cutting speed, air pressure, cutting height, or chosen current intensity greatly affect product quality. According to Bhowmicka et al. (2018), the common parameters which influence the cutting quality during $\mathrm{CNC}$ plasma cutting process are gas pressure, cutting current, arc voltage, standoff distance (distance between the material surfaces and the nozzle tip), cutting speed, and material thickness.

Various studies have been conducted on the cutting methods used in plasma machines. Salonitisa et al. (2012) investigated the plasma arc cutting process on S235 mild steel by CNC plasma cutting machine. In their research report, the stand-off distance had a significant effect on surface roughness and cut angle. Meanwhile, the effect of material thickness, cutting current, and cutting speed in the CNC plasma on the surface roughness was studied by establishing a fuzzy logic model by Ozek et al. (2011). Their results indicated that while cutting the material with the same sheet thickness, the surface roughness decreased with the increase in the cutting speed, and increased with the increase in the ampere. Bhowmicka et al. (2018) had an experimental investigation on the effect of cutting current, traverse speed of torch, and thickness on the variation of $\mathrm{Ra}$ value of surface roughness, temperature distribution, thickness of heataffected zone, and hardness for S235JR steel.

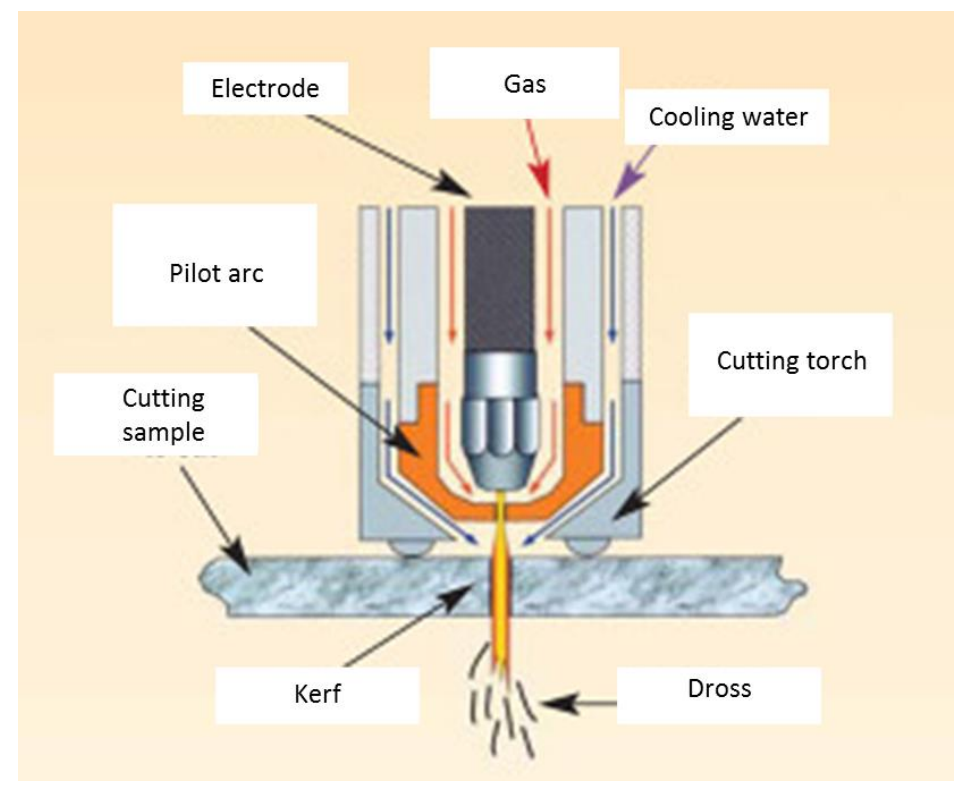

Figure 1. Plasma arc cutting principle (Tsiolikas et al., 2016) 
Losub et al. (2008) found that the electrical voltage and the cutting speed must be arranged in accordance with the properties and geometric shape of the material to be cut in order to achieve good plasma cutting results. A design of experiments approach was used to experimentally investigate the influence of cutting parameters on kerf characteristics. Kechagias et al. (2014) reported that on cutting of $15-\mathrm{mm}$ mild steel plates by plasma arc cutting process, the most influencing parameters on kerf characteristics were the cutting speed and the arc voltage. A mathematical model was established by Guo et al. (2010) for plasma cutting methods to improve the cutting parameters to a level better than normal conditions. As a result, it can be seen from the past research that the cutting quality of CNC plasma cutting process is evaluated by the ability to cut out the sample, the slag formation on the surface of the sample, the cut angle and the roughness of the cut surface. Among the output factors of the cutting process, the surface roughness should be considered the main output parameter to optimize the quality of the cutting surface. Moreover, in order to achieve higher cutting thickness with a higher quality of the cutting kerf, many parameters must be taken into careful consideration.

Although many studies have been carried out on $\mathrm{CNC}$ plasma cutting machines to investigate the influence of process parameters on cutting product quality, the existing research results are only applicable to a kind of steel with a given thickness. At the same time, the actual production normally used varied steel grades with different thicknesses. In particular, in Vietnam, the CT3 steel, a kind of low-carbon steel, is widely used in industry because of its good mechanical properties, such as hardness, tensile strength, and heat resistance. In general, cutting methods are usually applied for this steel in the plate form to produce flanges or codes, etc. Therefore, it is important to investigate the CNC plasma cutting process for this steel. In this study, an investigation was made on the effect of technological parameters such as gas pressure, cutting current, standoff distance, and cutting speed on the cutting quality of CNC plasma cutting process including the ability to cut out the sample, the slag formation on the surface of the sample, the cut angle, and the roughness of the cut surface. The experimental work was done by employing Bruco CNC plasma cutting equipment for the samples with different thicknesses. The analysis of the results was used to determine the contribution of each individual parameter to the cutting quality.

\section{Materials and Methods}

\section{Materials}

The CT3 steel in sheet plate form was used for the experimental study. The thicknesses of sheet plate form were 5 and $8 \mathrm{~mm}$, the thicknesses that are widely used in the manufacturing industry. Samples with dimensions of $70 \mathrm{~mm}$ in length and $50 \mathrm{~mm}$ in width were cut from the sheet plate form. The chemical composition and mechanical properties of CT3 are illustrated in Tables 1 and 2, respectively. The density of this steel was $7.85 \mathrm{~g} \mathrm{~cm}^{-3}$.

\section{Experimental setup}

The experiment was carried out on Bruco CNC plasma cutting machine (Figure 2). The equipment comprised of major parts such as air compressor, AC plug, power supply, plasma torch, ground clamp, electrode, nozzle, guide rail, computer, and cutting table. In this study, in order to cut CT3 steel, the gas selected in CNC plasma cutting was air. Compressed air was equipped in this cutting system to control the air pressure. This should be an important process parameter for investigation. In addition, the cutting speed was controlled by a modification of setting up in MicroStep software.

In this study, the experimental investigation was conducted for two cases of the thickness of sheet plate form of 5 and $8 \mathrm{~mm}$ by conventional experimental method and Taguchi method, respectively. The four-parameter design is shown in Table 3 including gas pressure $(\mathrm{P})$, cutting current (I), standoff distance $\left(l_{c}\right)$, and cutting speed (v) for the thickness of $5 \mathrm{~mm}$ following the conventional experimental methodology. The initial parameters of the first case of thickness were designed based on the referenced 
Table 1. Chemical composition of CT3 steel

\begin{tabular}{ccccccc}
\hline Steel & $\mathrm{C}$ & $\mathrm{Mn}$ & $\mathrm{Si}$ & $\mathrm{S}$ & $\mathrm{P}$ & $\mathrm{Fe}$ \\
\hline CT3 & $0.14-0.22$ & $0.40-0.60$ & $0.12-0.30$ & $\leq 0.05 \%$ & $\leq 0.04 \%$ & in balance \\
\hline
\end{tabular}

Table 2. Mechanical properties of CT3 steel

\begin{tabular}{ccc}
\hline$\sigma_{c}\left(\mathrm{~N} \mathrm{~mm}^{-2}\right)$ & $\sigma_{\mathrm{b}}\left(\mathrm{N} \mathrm{mm}^{-2}\right)$ & $\delta(\%)$ \\
\hline 225 & $373-461$ & 22 \\
\hline
\end{tabular}

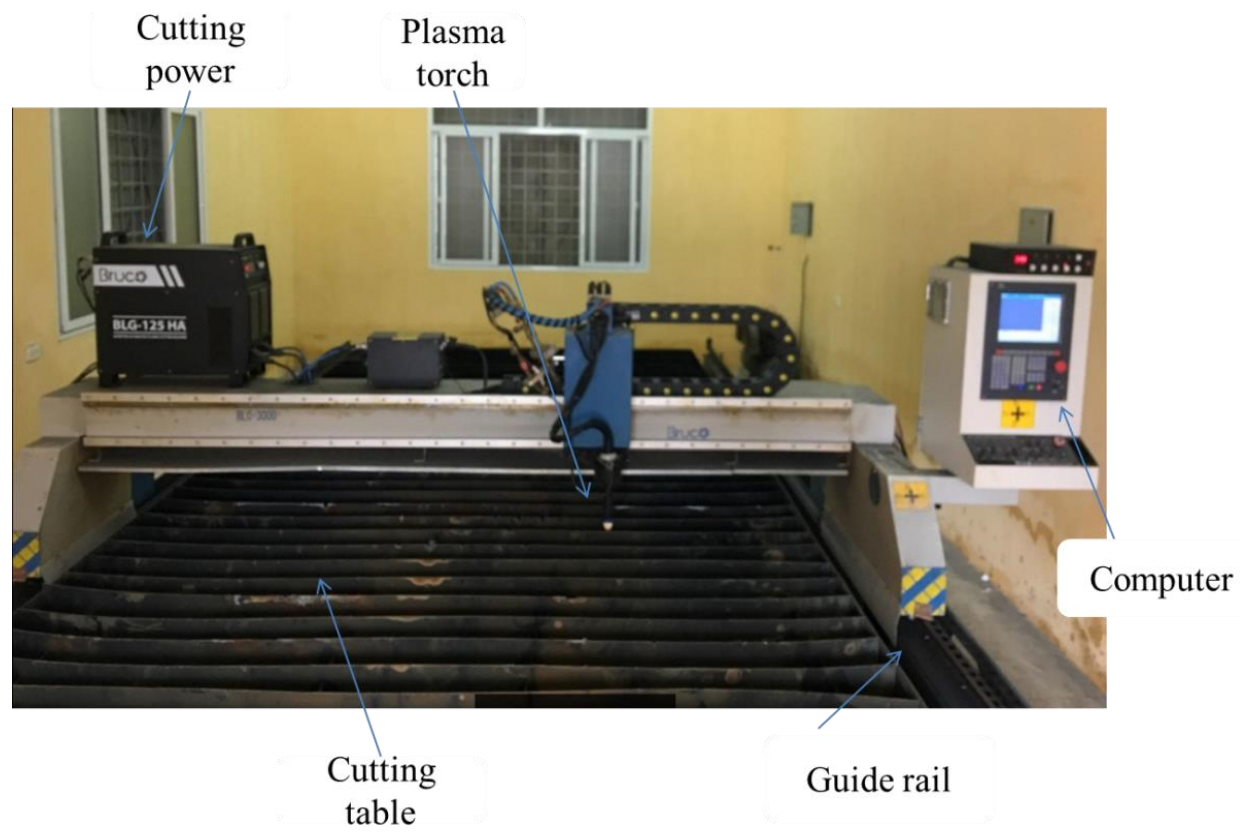

Figure 2. Bruco CNC plasma cutting machine

parameters of the equipment manufacturer for other grades of steel.

In this case, all parameters of the cutting quality of $\mathrm{CNC}$ plasma cutting process including the ability to cut out the sample, the slag formation on the surface of the sample, the cut angle, and the roughness of cut surface were evaluated.

Then, based on the obtained good results in the case of $5 \mathrm{~mm}$ in thickness, a design of experiment following the Taguchi method was carried out for the samples with a thickness of $8 \mathrm{~mm}$ in order to optimize the quality of the cutting surface. Taguchi method is a fractional factorial design method based on an orthogonal array method developed by Genichi Taguchi (Kumar, 2018). The Taguchi design method is a simple and robust technique for optimizing the process parameters. In this method, the main parameters, which are assumed to have an influence on process results, are located at different rows in a designed orthogonal array (Arakerimath \& Kumar, 2015). Furthermore, a larger number of experiments are required with an increase in the process parameters. This technique is used to find the best set of values of controllable factors to type the design less sensitive with a variation of noise, which means that Taguchi method makes a design more robust. There are three categories of performance characteristics as the larger the better, the Vietnam Journal of Agricultural Sciences 
smaller the better, and the nominal - the better (Colombo et al., 2009; Bahram, 2009). These performance characteristics were evaluated by the Signal-to-Noise ratio or simply known as the $\mathrm{S} / \mathrm{N}$ ratio as follows:

The larger - the better:

$$
\frac{S}{N}=-10 \log _{10}\left(\frac{1}{n} \sum_{i=1}^{n} \frac{1}{Y_{i}^{2}}\right)(1)
$$

The smaller - the better:

$$
S / N=-10 \log _{10}\left(\frac{1}{n} \sum_{i=1}^{n} Y^{2}\right)
$$

The nominal - the better:

$$
S / N=-10 \log _{10}\left(\frac{1}{n} \sum_{i=1}^{n}\left(Y_{i}-Y_{o}\right)^{2}\right)(3)
$$

where, $\mathrm{S} / \mathrm{N}$ is performance statistics, $\mathrm{n}$ is the number of repetitions for an experimental combination, $\mathrm{Y}_{\mathrm{i}}$ is the performance value of the $\mathrm{i}^{\text {th }}$ experiment, and $\mathrm{Y}_{\mathrm{o}}$ is the nominal desired value.

In this study, four input factors including gas pressure (P), cutting current (I), standoff distance $\left(l_{c}\right)$, and cutting speed $(v)$ with three levels were used as shown in Table 4. The standard L9 (34) orthogonal matrix experiment was used (Table 5) following the experiment design of Taguchi method.

\section{Output data measurement}

The quality of sample by plasma cutting process was examined by kerf characteristic, cut angle, and roughness of the cut surface. Two parameters of the kerf characteristic included the ability to cut out the sample and the slag formation on the surface of the sample. The slag formation was observed directly by the eyes. The cut angle was defined as shown in Figure 3 and measured by a universal bevel protractor.

Surface roughness changes depending on the cutting parameters. To observe the effect of cutting parameters on the roughness of the surface, the average surface of the sample was investigated. The surface roughness parameter measured on the cutting surface as shown in Figure 4 is $\mathrm{Rz}(\mu \mathrm{m}) . \mathrm{Rz}$ is the mean of five maximum peak-to-valley roughness depths in five successive sampling lengths. The measurements were taken by Mitutoyo Surftest RJ-210 tester (Figure 5).

\section{Results and Discussion}

\section{Experimental results in the case of a thickness of $5 \mathrm{~mm}$}

The experimental results obtained in the case of a thickness of $5 \mathrm{~mm}$ are indicated in Table 6.

Table 3. Parameters of experimental design for the sample with a thickness of $5 \mathrm{~mm}$

\begin{tabular}{ccccc}
\hline \multirow{2}{*}{ No. } & \multicolumn{3}{c}{ Process parameters } \\
\cline { 2 - 4 } & $\mathrm{I}(\mathrm{A})$ & $\mathrm{P}(\mathrm{MPa})$ & $\mathrm{I}_{\mathrm{c}}(\mathrm{mm})$ & $\mathrm{v}(\mathrm{mm} / \mathrm{min})$ \\
\hline 1 & 60 & 0.45 & 3.5 & 2000 \\
2 & 60 & 0.45 & 3.5 & 1800 \\
3 & 60 & 0.7 & 1.5 & 2000 \\
4 & 65 & 0.55 & 3.0 & 2000 \\
5 & 65 & 0.55 & 2.0 & 2000 \\
6 & 65 & 0.55 & 3.5 & 2000 \\
7 & 65 & 0.55 & 3.5 & 1800 \\
9 & 65 & 0.7 & 3.5 & 2200 \\
10 & 65 & 0.7 & 3.5 & 2000 \\
11 & 65 & 0.7 & 2.0 & 2000 \\
\hline
\end{tabular}


An investigation on the effect of cutting parameters in CNC plasma cutting process for carbon steel

Table 4. Parameters of experimental design for the sample with a thickness of $8 \mathrm{~mm}$

\begin{tabular}{cccccc}
\hline \multirow{2}{*}{ Thickness of sample $(\mathrm{mm})$} & No. & \multicolumn{4}{c}{ Process parameters } \\
\cline { 3 - 6 } & & $\mathrm{I}(\mathrm{A})$ & $\mathrm{v}\left(\mathrm{mm} \mathrm{min}^{-1}\right)$ & $\mathrm{I}_{\mathrm{c}}(\mathrm{mm})$ & $\mathrm{P}(\mathrm{MPa})$ \\
\hline \multirow{2}{*}{8} & Level 1 & 80 & 1000 & 1.5 & 0.6 \\
& Level 2 & 90 & 1200 & 3.5 & 0.7 \\
& Level 3 & 100 & 1500 & 4.0 & 0.8 \\
\hline
\end{tabular}

Table 5. Orthogonal array L9

\begin{tabular}{ccccc}
\hline No. & $\mathrm{I}_{\mathrm{c}}(\mathrm{mm})$ & $\mathrm{v}\left(\mathrm{mm} \mathrm{min}^{-1}\right)$ & $\mathrm{I}(\mathrm{A})$ & $\mathrm{P}(\mathrm{MPa})$ \\
\hline 1 & 1 & 1 & 1 & 1 \\
2 & 1 & 2 & 2 & 3 \\
3 & 1 & 3 & 3 & 3 \\
4 & 2 & 1 & 2 & 1 \\
5 & 2 & 2 & 3 & 2 \\
7 & 2 & 3 & 3 & 2 \\
9 & 3 & 1 & 1 & 3 \\
\hline
\end{tabular}

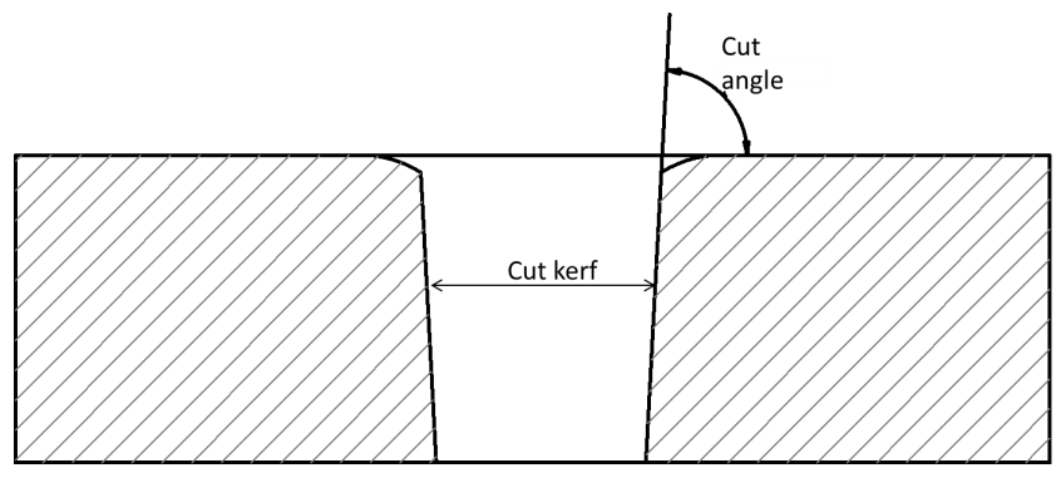

Figure 3. Determination of cut angle

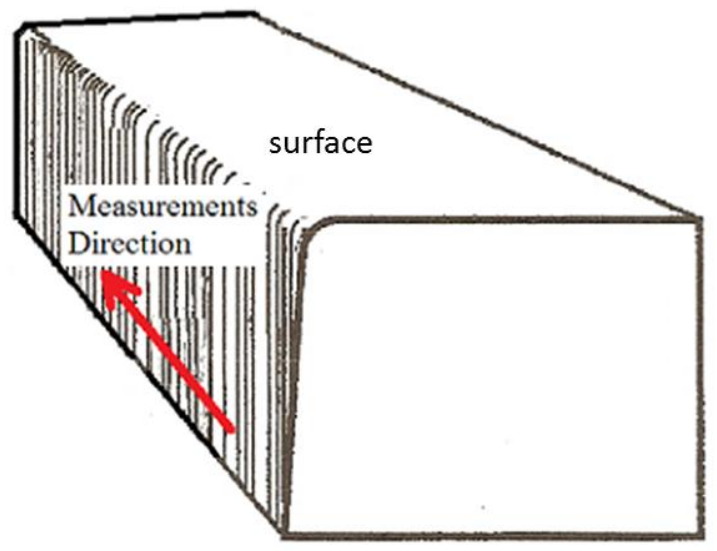

Figure 4. Determination of surface roughness 


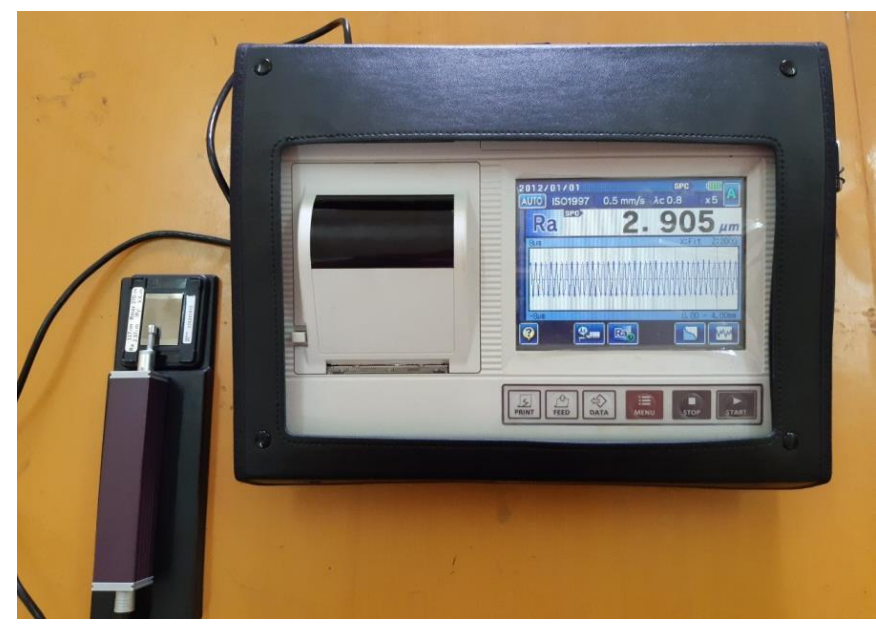

Figure 5. Mitutoyo Surftest RJ-210 test

As can be seen, at a low level of cutting current of about 60A, the sample could not be cut out in the case of high standoff distance and cutting speed but low gas pressure. When the pressure gas increased, the sample was able to be cut out. However, the quality of cutting kerf was not so high with slag formation on the surface and high roughness even though other process parameters were improved. Therefore, the value of cutting current should be achieved at a real level in order to enhance the quality of the cutting surface.

At a higher level of cutting current (65A), it can be clearly seen that the gas pressure strongly affected the output data. In detail, an increase in the gas pressure from $0.55 \mathrm{MPa}$ to $0.7 \mathrm{MPa}$ induced an improvement of the cutting angle as well as the roughness of the cutting surface. Moreover, the condition with a higher gas pressure would allow to set up a higher cutting speed in order to increase the cutting productivity. On the other hand, the standoff distance and cutting speed had an influence on the formation of slag. The formation of slag on the surface of the sample can be observed in Figure 6. Obviously, in order to obtain a higher quality of surface without slag, the standoff distance should be decreased and cutting speed should be set at a higher level.

Additionally, it can also be seen that the cutting surface became smoother in the case of a higher standoff distance. However, a higher value of standoff distance might induce a bevel for the cutting angle, leading to a decrease in the quality of the cutting surface. Thus, the standoff distance should be set at a suitable value to obtain satisfied values for surface roughness as well as cutting angle.

For the case of a thickness of $5 \mathrm{~mm}$, it can be said that the parameters of CNC plasma cutting process for CT3 steel should be chosen as $\mathrm{I}=$ $65 \mathrm{~A}, \mathrm{v}=2000 \mathrm{~mm} \mathrm{~min}^{-1}, 1_{\mathrm{c}}=2 \mathrm{~mm}$, and $\mathrm{P}=$ $0.7 \mathrm{MPa}$ in order to achieve a high quality of cutting surface. Moreover, the value of cutting current needed to be carefully set at a level higher than 60A to ensure the ability for cutting off the sample with $5 \mathrm{~mm}$ in thickness.

\section{Optimization of cutting quality using Taguchi approach}

The obtained experimental results are shown in Table 7. In this case, only the parameter of surface roughness was examined to obtain the optimized value. In general, the required value of cutting current in the case of a thickness of $8 \mathrm{~mm}$ was higher than that in the case of $5 \mathrm{~mm}$ when other parameters were setup at the same values in order to cut out the sample. An example of surface roughness curve evaluated by $\mathrm{Rz}$ is shown in Figure 7 with the experimental condition as $1_{\mathrm{c}}=1.5 \mathrm{~mm}, \mathrm{v}=1200 \mathrm{~mm} \mathrm{~min}^{-1}, \mathrm{I}=$ $90 \mathrm{~A}$, and $\mathrm{P}=0.7 \mathrm{MPa}$.

Based on the obtained values in Table 7, the method of analyze Taguchi design was applied to calculate the values of Signal to Noise Ratios and Means. The calculated results are shown in Table 8. 
An investigation on the effect of cutting parameters in CNC plasma cutting process for carbon steel

Table 6. Experimental results in the case of a thickness of $5 \mathrm{~mm}$

\begin{tabular}{|c|c|c|c|c|c|c|c|c|}
\hline \multirow[b]{2}{*}{ No. } & \multicolumn{4}{|c|}{ Process parameters } & \multicolumn{4}{|c|}{ Output parameters } \\
\hline & $\begin{array}{c}1 \\
(A)\end{array}$ & $\begin{array}{c}\mathrm{P} \\
(\mathrm{MPa})\end{array}$ & $\begin{array}{c}\mathrm{I}_{\mathrm{c}} \\
(\mathrm{mm})\end{array}$ & $\begin{array}{c}\mathrm{v} \\
\left(\mathrm{mm} \mathrm{min}^{-1}\right)\end{array}$ & $\begin{array}{l}\text { Cut out } \\
\text { ability }\end{array}$ & $\begin{array}{c}\text { Slag } \\
\text { formation }\end{array}$ & $\begin{array}{l}\text { Cutting } \\
\text { angle }\end{array}$ & $\begin{array}{l}\text { Surface roughness } \\
\qquad(\mu \mathrm{m})\end{array}$ \\
\hline 1 & 60 & 0.45 & 3.5 & 2000 & No & & & \\
\hline 2 & 60 & 0.45 & 3.5 & 1800 & Yes & Yes & $98^{\circ} 50^{\prime}$ & 22.420 \\
\hline 3 & 60 & 0.7 & 1.5 & 2000 & Yes & No & $93^{\circ} 8^{\prime}$ & 12.761 \\
\hline 4 & 65 & 0.55 & 3.0 & 2000 & Yes & Yes & $95^{\circ} 50^{\prime}$ & 15.979 \\
\hline 5 & 65 & 0.55 & 2.0 & 2000 & Yes & Yes & $94^{\circ} 32^{\prime}$ & 17.674 \\
\hline 6 & 65 & 0.55 & 3.5 & 2000 & Yes & Yes & $95^{\circ} 36^{\prime}$ & 16.947 \\
\hline 7 & 65 & 0.55 & 3.5 & 1800 & Yes & Yes & $96^{\circ} 12^{\prime}$ & 16.850 \\
\hline 8 & 65 & 0.7 & 3.5 & 2200 & Yes & No & $93^{\circ} 20^{\prime}$ & 9.136 \\
\hline 9 & 65 & 0.7 & 3.5 & 2000 & Yes & Yes & $94^{\circ} 18^{\prime}$ & 8.560 \\
\hline 10 & 65 & 0.7 & 2.0 & 2000 & Yes & No & $91^{\circ} 28^{\prime}$ & 9.133 \\
\hline 11 & 65 & 0.7 & 1.5 & 2000 & Yes & No & $90^{\circ} 20^{\prime}$ & 10.989 \\
\hline
\end{tabular}

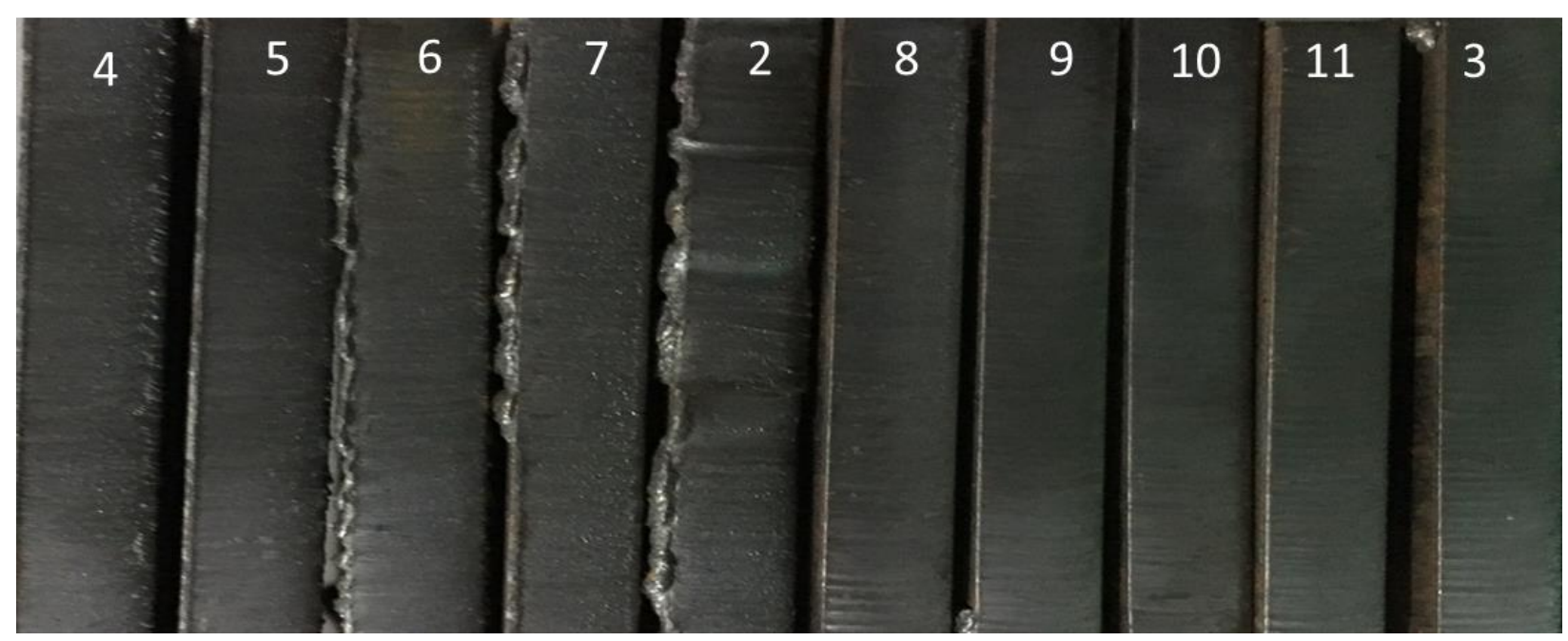

Figure 6. The appearance of cutting surface of sample with a thickness of $5 \mathrm{~mm}$

Table 7. The experimental results for sample with a thickness of $8 \mathrm{~mm}$

\begin{tabular}{cccccc}
\hline No. & $\mathrm{I}_{\mathrm{c}}(\mathrm{mm})$ & $\mathrm{V}\left(\mathrm{mm} \mathrm{min}^{-1}\right)$ & $\mathrm{I}(\mathrm{A})$ & $\mathrm{P}(\mathrm{MPa})$ & Roughness $(\square \mathrm{m})$ \\
\hline 1 & 1.5 & 1000 & 80 & 0.6 & 12.109 \\
2 & 1.5 & 1200 & 90 & 0.7 & 11.180 \\
3 & 1.5 & 1500 & 100 & 0.8 & 9.759 \\
4 & 2.0 & 1000 & 90 & 0.8 & 14.144 \\
5 & 2.0 & 1200 & 100 & 0.6 & 14.740 \\
6 & 2.0 & 1500 & 80 & 0.7 & 17.527 \\
7 & 3.5 & 1000 & 100 & 0.7 & 16.578 \\
8 & 3.5 & 1200 & 80 & 0.8 & 11.140 \\
9 & 3.5 & 1500 & 90 & 0.6 & 9.613 \\
\hline
\end{tabular}




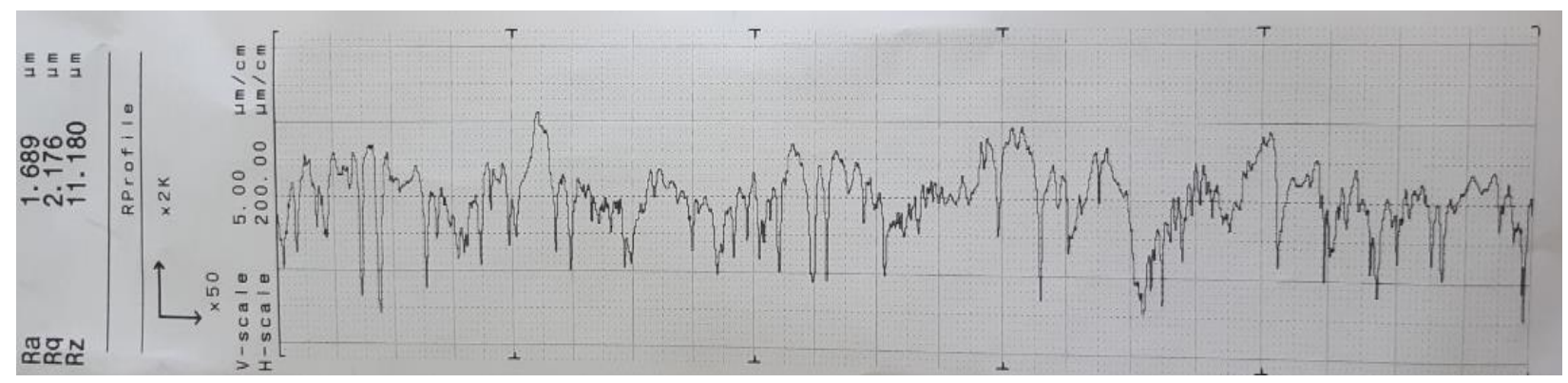

Figure 7. An example of roughness curve in the experimental condition as $I_{c}=1.5 \mathrm{~mm}, \mathrm{v}=1200 \mathrm{~mm} \mathrm{~min}^{-1}, \mathrm{I}=90 \mathrm{~A}$, and $\mathrm{P}=0.7 \mathrm{MPa}$

Table 8. Analyze Taguchi design

\begin{tabular}{cccccccc}
\hline No. & $\mathrm{I}_{\mathrm{c}}(\mathrm{mm})$ & $\mathrm{v}\left(\mathrm{mm} \mathrm{min}^{-1}\right)$ & $\mathrm{I}(\mathrm{A})$ & $\mathrm{P}(\mathrm{MPa})$ & Roughness $(\mu \mathrm{m})$ & $\mathrm{S} / \mathrm{N}$ & Means \\
\hline 1 & 1.5 & 1000 & 80 & 0.6 & 12.109 & -21.6622 & 12.109 \\
2 & 1.5 & 1200 & 90 & 0.7 & 11.180 & -20.9688 & 11.180 \\
3 & 1.5 & 1500 & 100 & 0.8 & 9.759 & -19.7881 & 9.759 \\
4 & 2.0 & 1000 & 90 & 0.8 & 14.144 & -23.0114 & 14.144 \\
5 & 2.0 & 1200 & 100 & 0.6 & 14.740 & -23.3699 & 14.740 \\
6 & 2.0 & 1500 & 80 & 0.7 & 17.527 & -24.8742 & 17.527 \\
7 & 3.5 & 1000 & 100 & 0.7 & 16.578 & -24.3906 & 16.578 \\
8 & 3.5 & 1200 & 80 & 0.8 & 11.140 & -20.9377 & 11.140 \\
9 & 3.5 & 1500 & 90 & 0.6 & 9.613 & -19.6572 & 9.613 \\
\hline
\end{tabular}

Figure 8 indicates the main effects plot for (a) Means and (b) S/N ratios. Since the smaller level of roughness was the better, the lower value for Mean was expected to achieve. Thus, the experimental condition with $l_{c}$ of $1.5 \mathrm{~mm}$ was considered a good condition for surface roughness. When the torch was positioned too high with regard to the surface of the sample, the plasma arc was long and curve. This also resulted in the formulation of drag-lines and surface waves, leading to an increase in the roughness of surface. At the same value of cutting current and gas pressure, the higher level of cutting speed induced a decrease in the roughness of cutting surface. This phenomenon could also be seen in the case of a lower thickness of $5 \mathrm{~mm}$. That could be explained by the fact that a too low cutting speed led to over-melting of the processing area that could not be removed and re-solidified within the cutting area. This re-solidification was in the form of striations, thereby increasing the surface roughness.

At the same time, according to the Taguchi method, the higher value for $\mathrm{S} / \mathrm{N}$ ratios should be chosen for optimizing the parameters. As a result, the experiment should be set up as $1_{\mathrm{c}}=1.5 \mathrm{~mm}, \mathrm{v}$ $=1500 \mathrm{~mm} \mathrm{~min}^{-1}, \mathrm{I}=90 \mathrm{~A}$, and $\mathrm{P}=0.8 \mathrm{MPa}$. In this condition, the best value of the roughness of the surface can be achieved.

On the other hand, the influence of cutting parameters on the surface roughness is shown in Table 9. In this table, the standoff distance is the most important parameter. The value of $l_{c}$ should be carefully examined during $\mathrm{CNC}$ plasma cutting. Then, the pressure of cutting gas also considerably affectedt the quality of the cutting surface. However, the cutting speed was a minor influencing parameter; while the effect of cutting current could not be seen clearly.

\section{Conclusions}

In this study, the experiments weres conducted on the CNC plasma cutting process of CT3 steel to examine the influence of the process parameters including the standoff distance, cutting current, gas pressure, and cutting speed for two cases of thickness of samples. The quality 

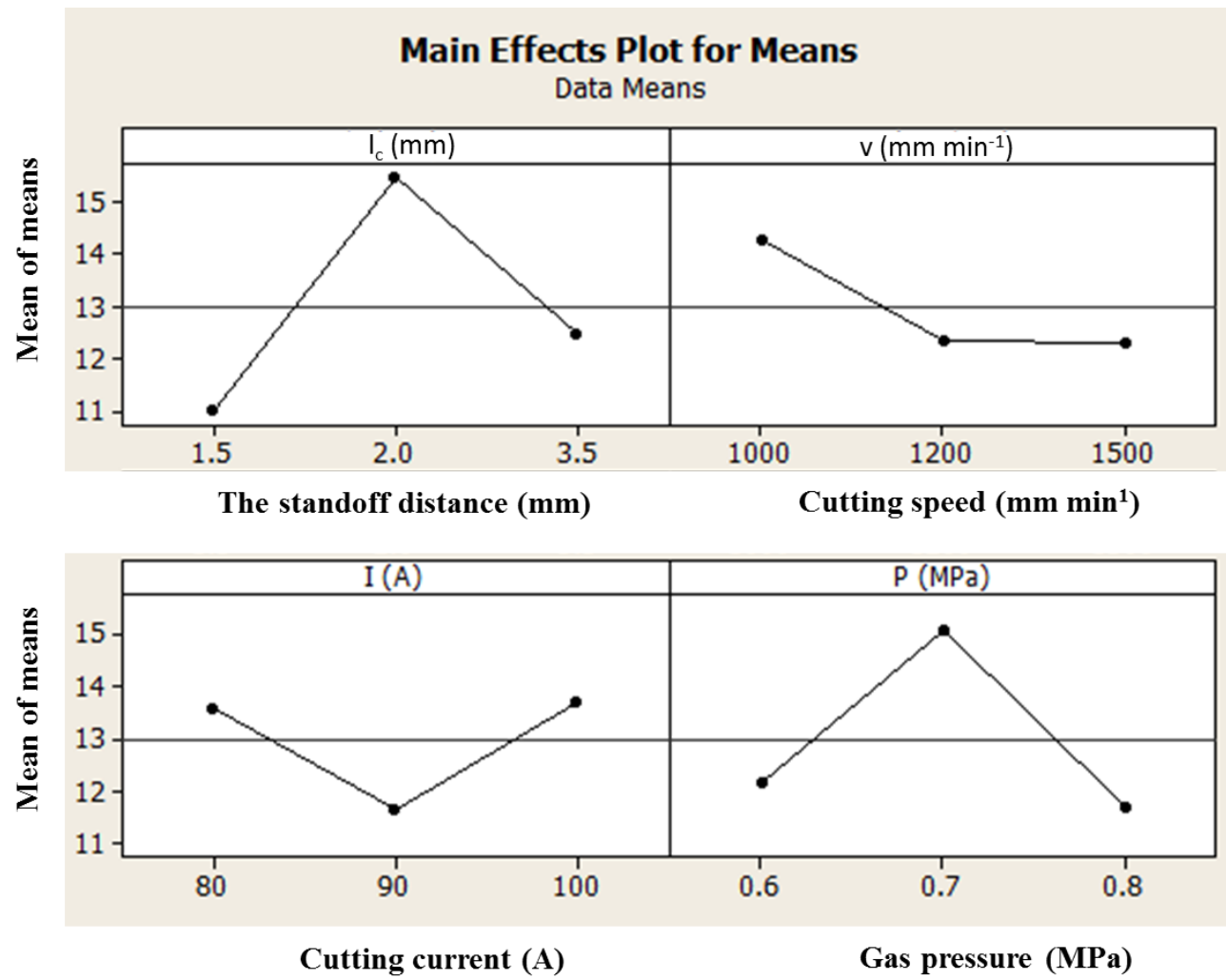

(a)

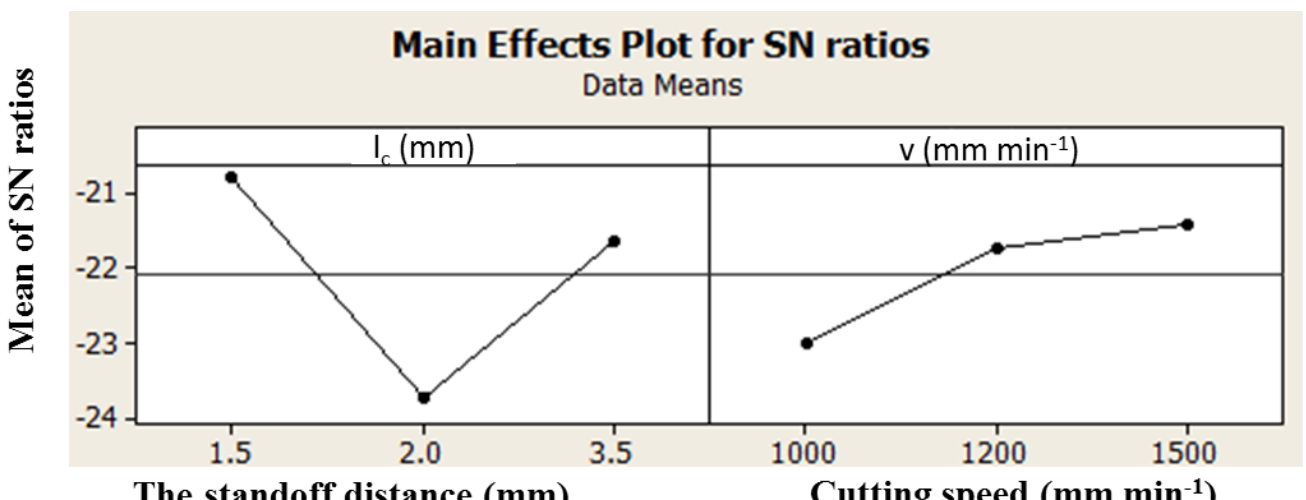

The standoff distance $(\mathrm{mm})$

Cutting speed (mm min $\left.^{-1}\right)$

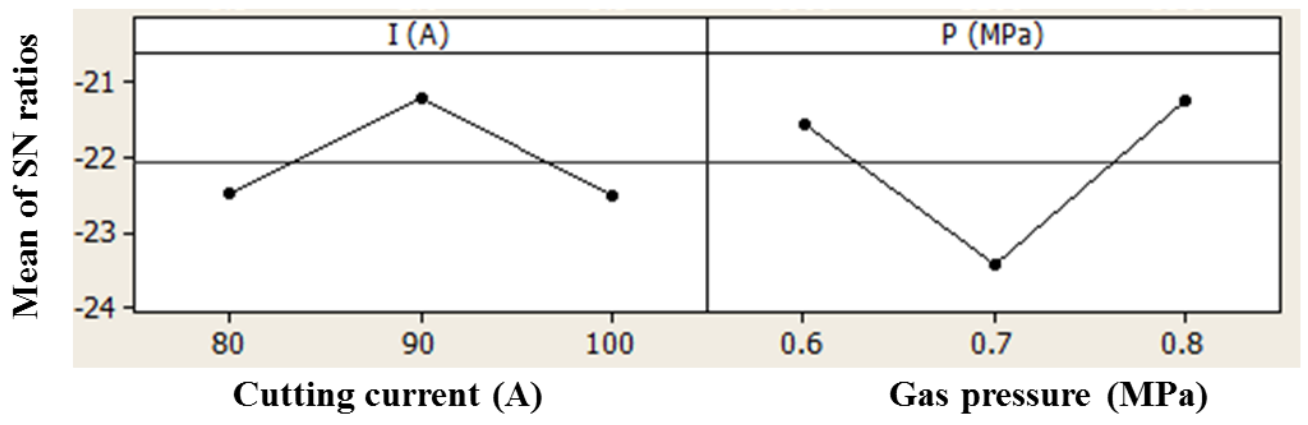

Signal-to-noise: Smaller is better

(b)

Figure 8. Main effects plot for (a) Means and (b) S/N ratios 
Table 9. Response table for Signal to Noise Ratios

\begin{tabular}{ccccc}
\hline Level & $\mathrm{I}_{\mathrm{c}}(\mathrm{mm})$ & $\mathrm{v}\left(\mathrm{mm} \mathrm{min}^{-1}\right)$ & $\mathrm{I}(\mathrm{A})$ & $\mathrm{P}(\mathrm{MPa})$ \\
\hline 1 & -20.81 & -23.02 & -22.49 & -21.56 \\
2 & -23.75 & -21.76 & -21.21 & -23.41 \\
3 & -21.66 & -21.44 & -22.52 & -21.25 \\
Delta & 2.95 & 1.58 & 1.30 & 2.17 \\
Rank & 1 & 3 & 4 & 2 \\
\hline
\end{tabular}

characteristics assessed in the study included the ability to cut out the sample, the slag formation on the surface, the surface roughness, and the cut angle. Some concluding remarks can be derived as follows:

The value of cutting current should be set at a real value in order to cut out of the sample. When the thickness of the sample increases, the required cutting current needs to be higher.

The air pressure strongly affects the slag formation. At higher air pressure, the slag formation might be reduced.

Using design of experiments and analysis of variance, it is found that the surface roughness is mainly affected by the standoff distance and air pressure, whereas the cutting speed and cutting current are the minor influencing parameters.

For the case of a thickness of $5 \mathrm{~mm}$, it can be said that the parameters of CNC plasma cutting process for CT3 steel should be chosen as $\mathrm{I}=$ $65 \mathrm{~A}, \mathrm{v}=2000 \mathrm{~mm} \mathrm{~min}^{-1}, 1_{\mathrm{c}}=2 \mathrm{~mm}$, and $\mathrm{P}=$ $0.7 \mathrm{MPa}$ in order to achieve high quality of cutting surface. Moreover, the value of cutting current needs to be carefully set at a level higher than $60 \mathrm{~A}$ to ensure the ability for cutting off the sample with $5 \mathrm{~mm}$ in thickness. In the case of $8 \mathrm{~mm}$ in thickness, the experiment should be set up as $\mathrm{I}=90 \mathrm{~A}, \mathrm{v}=2000 \mathrm{~mm} \mathrm{~min}^{-1}, 1_{\mathrm{c}}=1.5 \mathrm{~mm}$, and $\mathrm{P}=0.8 \mathrm{MPa}$ to obtain the best value of roughness surface.

\section{References}

Arakerimath R. \& Kumar V. (2015). Taguchi based parametric analysis and optimization of power consumption and kerf in plasma arc machining. International Journal of Engineering and Management Research. Special Issue: 12-16.
Bahram A. (2009). Optimising the automated plasma cutting process by design of experiments. International Journal of Rapid Manufacturing. 1(1): 19-40.

Bhowmicka S., Basub J., Majumdarc G. \& Bandyopadhyayc A. (2018). Experimental study of plasma arc cutting of AISI 304 stainless steel. Materials Today: Proceedings. 5: 4541-4550.

Colombo V., Concetti A., Dallavalle S., Fazziioli R., Ghedini E. \& Vancini M. (2009). Optimization of plasma arc cutting of mild steel thin plates. Journal of High Temperature Material Processes. 13(3): 267-285.

Guo S., Zhou Q., Guo W. \& Xu P. (2010). Computational analysis of a double nozzle structure plasma cutting torch. Plasma Chemistry and Plasma Processing. 30: 121-140.

Ilii S. M., Coteata M. \& Munteanu A. (2010). Experimental results concerning the variation of surface roughness parameter $(\mathrm{Ra})$ at plasma arc cutting of a stainless steel workpiece. International Journal of Modern Manufacturing Technologies. 2(1): 31-36.

Kechagias J., Stavropoulos P., Maropoulos S. \& Salonitis K. (2014). On the multi-parameter optimization of CNC plasma-arc cutting process quality indicators using Taguchi Design of Experiments. The $13^{\text {th }}$ International Conference on Instrumentation, Measurement, Circuits and Systems - IMCAS '14. December 15-17, 2014. Istanbul, Turkey. 128-133.

Kumar S. (2018). Experimental study on parameters optimization in CNC plasma arc cutting (AISI 206 steel) using Taguchi approach. International Journal of Technical Research and Science. 3(6): 198-205.

Losub A., Nagit G. \& Neguescu F. (2008). Plasma cutting of composite materials. International Journal of Material Forming Supply. 1: 1347-1350.

Ozek C., Caydas U. \& Unal E. (2011). A fuzzy model for predicting surface roughness in plasma arc cutting of AISI 4140 stell. Materials and Manufacturing Processes. 27(1): 95-102.

Salonitisa K. \& Vatousianosb S. (2012). Experimental investigation of the plasma arc cutting process. Procedia CIRP. 3: 287-292

Patela P., Sonia S., Kotkundeb N. \& Khannaa N. (2018). Study the effect of process parameters in plasma arc cutting on Quard-400 material using analysis of variance. Materials Today: Proceedings. 5: 6023-6029. 
Teja S. S., Karthik G., Sampath S. \& Shai M. (2015). Experimental investigation to study the impact of machining parameters on mild steel using plasma arc cutting. International Journal of Engineering Research and Applications. 5(8): 83-88.
Tsiolikas A., Kechagias J. \& Salonitis K. (2016). Optimization of cut surface quality during CNC plasma arc cutting process. International Journal of Systems Application, Engineering and Development. 10: 305-308. 